\title{
Asthma-COPD overlap syndrome (ACOS) in primary care of four Latin America countries: the PUMA study
}

\author{
Maria Montes de Oca ${ }^{1 *}$, Maria Victorina Lopez Varela², Maria E. Laucho-Contreras', Alejandro Casas ${ }^{3}$,
} Eduardo Schiavi ${ }^{4}$ and Juan Carlos Mora ${ }^{5}$

\begin{abstract}
Background: Asthma-COPD overlap syndrome (ACOS) prevalence varies depending on the studied population and definition criteria. The prevalence and clinical characteristics of ACOS in an at-risk COPD primary care population from Latin America was assessed.

Methods: Patients $\geq 40$ years, current/ex-smokers and/or exposed to biomass, attending routine primary care visits completed a questionnaire and performed spirometry. COPD was defined as post-bronchodilator forced expiratory volume in $1 \mathrm{~s} /$ forced vital capacity $\left(F E V_{1} / F V C\right)<0.70$; asthma was defined as either prior asthma diagnosis or wheezing in the last 12 months plus reversibility (increase in post-bronchodilator FEV ${ }_{1}$ or FVC $\geq 200 \mathrm{~mL}$ and $\geq 12 \%$ ); ACOS was defined using a combination of COPD with the two asthma definitions. Exacerbations in the past year among the subgroups were evaluated.
\end{abstract}

Results: One thousand seven hundred forty three individuals completed the questionnaire, 1540 performed acceptable spirometry, 309 had COPD, 231 had prior asthma diagnosis, and 78 asthma by wheezing + reversibility. ACOS prevalence in the total population (by post-bronchodilator $\mathrm{FEV}_{1} / \mathrm{FVC}<0.70$ plus asthma diagnosis) was 5.3 and $2.3 \%$ by postbronchodilator $\mathrm{FEV}_{1} / \mathrm{FVC}<0.70$ plus wheezing + reversibility. In the obstructive population (asthma or COPD), prevalence rises to 17.9 and $9.9 \%$ by each definition, and to 26.5 and $11.3 \%$ in the COPD population. ACOS patients defined by postbronchodilator $\mathrm{FEV}_{1} / \mathrm{FVC}<0.7$ plus wheezing + reversibility had the lowest lung function measurements. Exacerbations for ACOS showed a prevalence ratio of 2.68 and 2.20 (crude and adjusted, $p<0.05$, respectively) (reference COPD).

Conclusions: ACOS prevalence in primary care varied according to definition used. ACOS by post-bronchodilator $\mathrm{FEV}_{1} /$ FVC $<0.7$ plus wheezing + reversibility represents a clinical phenotype with more frequent exacerbations, which is probably associated with a different management approach.

Keywords: ACOS, Latin America, Prevalence, PUMA

\section{Background}

Both chronic obstructive pulmonary disease (COPD) and asthma are common chronic airway diseases that contribute to morbidity and mortality in adults worldwide. The coexistence of these two pathologies in some individuals is recognised as asthma-COPD overlap syndrome (ACOS). The prevalence of this phenotype varies

\footnotetext{
* Correspondence: montesdeoca.maria@gmail.com

${ }^{1}$ Servicio de Neumonología, Hospital Universitario de Caracas, Facultad de Medicina, Los Chaguaramos, 1030, Universidad Central de Venezuela, Caracas, Venezuela

Full list of author information is available at the end of the article
}

considerably between different studies and this is primarily related to the heterogeneity of the criteria used to define asthma and COPD, and the population being studied (e.g. general population, asthma, COPD).

The prevalence of ACOS in the total population ranges from 1.6 to $4.5 \%$ in different studies around the world [1-5]. If only subjects with asthma or COPD are included, the prevalence of ACOS among patients with COPD ranges from 12.1 to $55.2 \%$, and among patients with asthma from 13.3 to $61.0 \%$ [1-19]. The wide variation in prevalence is related to the diagnostic criteria applied when defining asthma (self-reported physician diagnosis vs. clinical and/ 
or spirometry-based diagnosis) and COPD (self-reported physician diagnosis vs. spirometric criteria: forced expiratory volume in $1 \mathrm{~s} /$ forced vital capacity $\left[\mathrm{FEV}_{1} / \mathrm{FVC}\right]$ $<0.70$ ), together with the population being studied.

Little is known regarding the prevalence of ACOS in Latin America. The Latin American Project for the Investigation of Lung Disease (PLATINO) populationbased study showed that two different definitions of asthma resulted in varied ACOS prevalence estimates in the same population [3]. The prevalence of ACOS based on post-bronchodilator $\mathrm{FEV}_{1} / \mathrm{FVC}<0.70$ and the presence of wheezing in the last year plus reversibility was estimated to be $1.8 \%$, compared with $2.9 \%$ when using post-bronchodilator $\mathrm{FEV}_{1} / \mathrm{FVC}<0.70$ and physician diagnosis of asthma [3].

Data from two recent systematic reviews suggest that ACOS is associated with more frequent adverse outcomes than either asthma or COPD. ACOS patients have shown higher healthcare utilisation, higher exacerbation rates, more symptoms and lower health-related quality of life (HRQOL) [20, 21]. However, in contrast to this, results from the COPD History Assessment In SpaiN (CHAIN) study showed that survival after 1 year of follow-up was better in ACOS patients than in clinically similar patients with COPD without any ACOS criteria. In addition, the authors reported that this phenotype was not associated with any other baseline clinical differences or worse clinical outcomes [22].

To our knowledge, limited information exists on the prevalence and clinical characteristics of ACOS phenotype in primary care [23]. Therefore, the aims of this study were to measure the prevalence of ACOS using different definitions in an at-risk COPD population ( $\geq 40$ years) attending primary care settings in four Latin American countries, to assess the clinical characteristics of these subjects, and to determine the association between ACOS and the following clinical outcomes: exacerbation, hospitalisation and dyspnoea severity.

\section{Methods}

The Prevalence StUdy and Regular Practice, Diagnosis and TreatMent, Among General Practitioners in Populations at Risk of COPD in Latin America (PUMA) study was conducted in the primary care setting of four Latin American countries: Argentina, Colombia, Venezuela, and Uruguay. Complete details of the methodology have been published previously [24-27]. In summary, this was a multicentre, multinational, cross-sectional, non-interventional study. Participating sites were selected according to local feasibility based on a previous local availability database of potential principal investigators (not randomised) and included primary care centres (family doctors, general practitioners etc.) with no direct connection with respiratory medicine specialists. These sites were selected to reflect the reality of national primary care practice in terms of geographical distribution and healthcare sector. The ethics committees for each site involved in the study approved the protocol and all participants provided written informed consent.

At-risk patients were included in the study if they were $\geq 40$ years of age, current or ex-smokers $(\geq 10$ pack-years, $\geq 50$ pipes/year or $\geq 50$ cigars/year) [28] and/ or exposed to biomass smoke (wood or coal for cooking and heating; exposure $\geq 100 \mathrm{~h} /$ year) $[29,30]$.

Participants completed a modified version of the PLATINO study questionnaire [31] for information on factors associated with COPD; these included demographics, smoking habits, education, employment, respiratory symptoms that included a question on wheezing in the last 12 months, comorbidities, use of respiratory medication and prior spirometric testing. Data on prior medical diagnosis of tuberculosis, asthma, chronic bronchitis, emphysema, and COPD were also obtained. A comorbidity score was calculated [32]. Spirometry was performed using the portable, battery-operated ultrasound Easy One spirometer (ndd Medical Technologies, Zurich, Switzerland). Spirometry tests were performed at baseline and $15 \mathrm{~min}$ after the inhalation of $400 \mu \mathrm{g}$ salbutamol, according to the American Thoracic Society (ATS) criteria of acceptability and reproducibility [33].

For the purpose of this study, the following definitions of asthma, COPD and ACOS were used:

1. COPD: A ratio of post-bronchodilator $\mathrm{FEV}_{1} / \mathrm{FVC}<0.70$ (GOLD definition) [34].

2. Asthma: Two definitions were used: (A) medical diagnosis of asthma (self-reported prior medical diagnosis); (B) the presence of wheezing in the last 12 months plus reversibility (post-bronchodilator increase in $\mathrm{FEV}_{1}$ or $\mathrm{FVC}$ of $200 \mathrm{~mL}$ and $12 \%$ ).

3. ACOS: Two definitions of ACOS validated in a previous study were used in the present study [3]. The combination of the COPD definition above with both asthma criteria separately: (A) a ratio of postbronchodilator $\mathrm{FEV}_{1} / \mathrm{FVC}<0.70$ plus prior medical diagnosis of asthma; (B) a ratio of post-bronchodilator $\mathrm{FEV}_{1} / \mathrm{FVC}<0.70$ and wheezing in the last 12 months plus reversibility (post-bronchodilator increase in $\mathrm{FEV}_{1}$ or $\mathrm{FVC}$ of $200 \mathrm{~mL}$ and $12 \%$ ).

Severity of COPD airway obstruction and disease stratification were determined using the GOLD criteria [34].

\section{Outcomes}

Dyspnea by the mMRC scale and COPD exacerbation among the subgroups were evaluated. COPD exacerbations were self-reported and defined by deterioration of breathing symptoms that affected usual daily activities or 
caused absences from work. We examined the proportion of subjects in each group who reported: 1) any exacerbation within the previous 12-months; 2) an exacerbation requiring a hospitalisation within the previous 12-months. We also examined the number of the exacerbation-related events within the previous 12-months.

\section{Statistical analysis}

Descriptive statistics were calculated using absolute and relative frequencies for categorical variables and means (median) and standard deviation (interquartile range) for numerical ones. For comparisons among numerical variables an ANOVA was used and a chi-squared test was used for comparisons between categorical variables. A $p$-value of $<0.05$ was considered statistically significant. Crude and adjusted Poisson regression models were performed in order to obtain the prevalence ratio for outcomes and each independent variable. A Wald test for heterogeneity or for trend (in specific cases) was considered. All analyses were performed using Stata 13.0 statistical software.

\section{Results}

A total of 1743 individuals completed study questionnaire and 1540 performed acceptable spirometry. Figure 1 is a Venn diagram displaying the overlap of the different diagnoses among these subjects. In the total PUMA study population, 1049 subjects did not have asthma, COPD or ACOS. Based on post-bronchodilator $\mathrm{FEV}_{1} / \mathrm{FVC}<0.70$ criteria, COPD was present in 309 patients; 231 patients had a medical diagnosis of asthma and 78 patients had asthma defined by reversibility plus wheezing. ACOS, defined as an asthma medical diagnosis and COPD was present in 82 patients, and defined by reversibility plus wheezing and COPD in 35 patients (Fig. 1).

Figure 2 shows the prevalence of ACOS according to different definitions used in the different populations (i.e. the denominator used when calculating prevalence). As expected, ACOS prevalence depends on the population

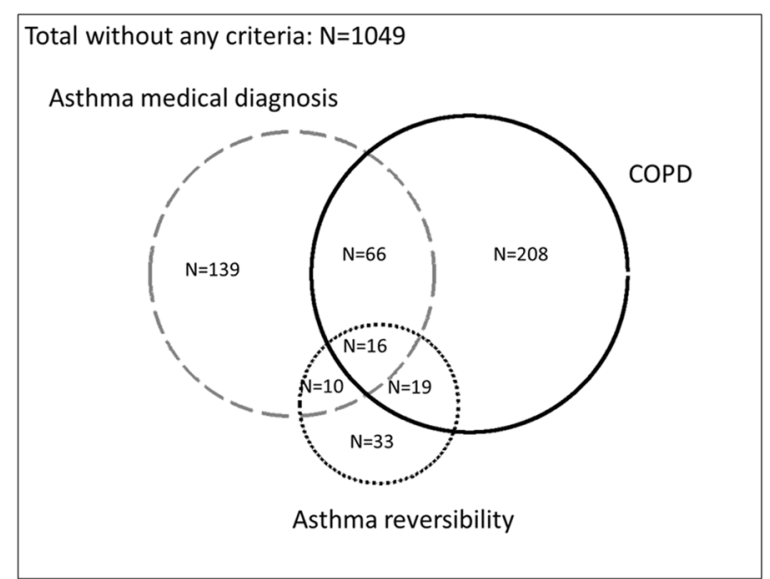

Fig. 1 Venn diagram showing the three phenotypes and the overlap in the PUMA study

(denominator) chosen: total study population, obstructive population (those affected with either asthma or COPD) or COPD population. The prevalence of ACOS in the total study population defined as asthma medical diagnosis plus $\mathrm{FEV}_{1} / \mathrm{FVC}<0.70$ was higher (5.3\%; 82/1540 subjects) than when using the reversibility plus wheezing and $\mathrm{FEV}_{1} /$ FVC $<0.70$ definition $(2.3 \% ; 35 / 1540$ subjects). A similar trend in ACOS prevalence was found in the obstructive population $(82 / 458$ subjects, $17.9 \%$ by asthma medical diagnosis and $\mathrm{FEV}_{1} / \mathrm{FVC}<0.70$ definition; and $35 / 352$ subjects, $9.9 \%$ by reversibility plus wheezing and $\mathrm{FEV}_{1} / \mathrm{FVC}<0.70$ definition) and the COPD population $(82 / 309$ subjects, $26.5 \%$ by asthma medical diagnosis and $\mathrm{FEV}_{1} / \mathrm{FVC}<0.70$ definition; and $35 / 309$ subjects, $11.3 \%$ by reversibility plus wheezing and $\mathrm{FEV}_{1} / \mathrm{FVC}<0.70$ definition).

The characteristics of subjects with COPD, asthma and ACOS according to the definition of COPD and asthma (wheezing + reversibility) are shown in Table 1 . Using these definitions, there were no differences in biomass smoke exposure or comorbidities between the groups. However, subjects in the asthma group were

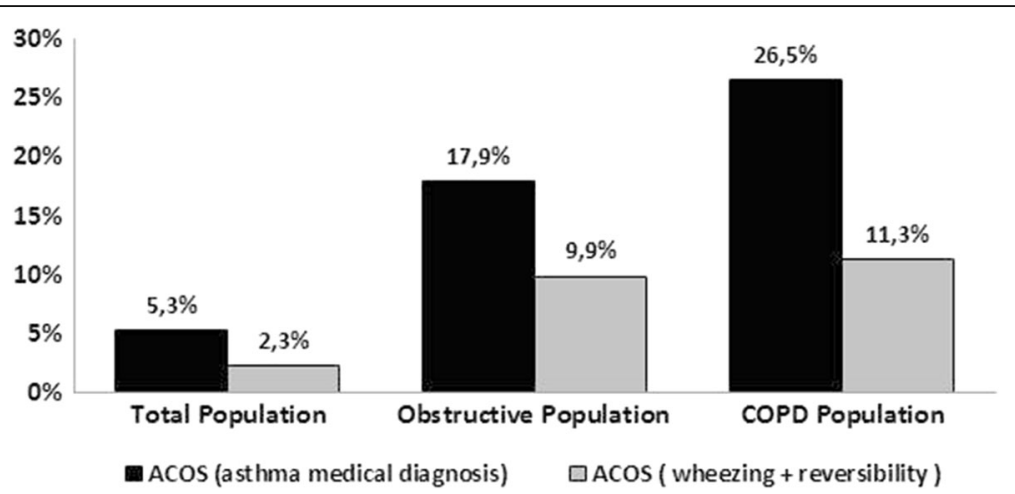

Fig. 2 ACOS prevalence using the different definitions (post-bronchodilator $\mathrm{FEV}_{1} / \mathrm{FVC}<0.70$ plus wheezing + reversibility, and post-bronchodilator $\mathrm{FEV}_{1} / \mathrm{FVC}<0.70$ plus medical diagnosis of asthma) in different populations: total population, obstructive population (asthma + COPD), or COPD population 
Table 1 Characteristics of subjects with COPD (post-bronchodilator FEV $1 / F V C<0.70$ ), asthma (wheezing + reversibility) and ACOS (post-bronchodilator $\mathrm{FEV}_{1} / \mathrm{FVC}<0.70$ plus wheezing + reversibility)

\begin{tabular}{|c|c|c|c|c|}
\hline \multirow[t]{2}{*}{ Variables } & \multirow{2}{*}{$\begin{array}{l}\text { Asthma } \\
(N=43)\end{array}$} & \multirow{2}{*}{$\begin{array}{l}\text { COPD } \\
(N=274)\end{array}$} & \multirow{2}{*}{$\begin{array}{l}\text { ACOS } \\
(N=35)\end{array}$} & \multirow[t]{2}{*}{$p$-value } \\
\hline & & & & \\
\hline Age, years, mean (SD) & $56.3(8.9)$ & $67.3(9.4)$ & $65.2(8.6)$ & $<0.001$ \\
\hline \multicolumn{2}{|l|}{ Age, complete years, n (\%) } & & & $<0.001$ \\
\hline $40-49$ & $10(23.3)$ & $6(2.2)$ & $1(2.9)$ & \\
\hline $50-59$ & $19(44.2)$ & $61(22.3)$ & $10(28.6)$ & \\
\hline$\geq 60$ & $14(32.5)$ & $20(75.6)$ & $24(68.6)$ & \\
\hline Gender male, n (\%) & $20(46.5)$ & $150(54.7)$ & $23(65.7)$ & 0.029 \\
\hline $\mathrm{BMI}, \mathrm{kg} / \mathrm{m}^{2}$, mean $(\mathrm{SD})$ & $29.9(6.2)$ & $26.4(6.0)$ & $26.0(4.9)$ & 0.009 \\
\hline \multicolumn{2}{|l|}{$\mathrm{BMI}, \mathrm{kg} / \mathrm{m}^{2}, \mathrm{n}(\%)$} & & & 0.015 \\
\hline$<25$ & $10(23.3)$ & $125(45.6)$ & $13(37.1)$ & \\
\hline $25-29.9$ & $15(34.9)$ & $93(33.9)$ & $14(40.0)$ & \\
\hline$\geq 30$ & $18(41.9)$ & $56(20.4)$ & $8(22.9)$ & \\
\hline Smoking, pack-years, mean (SD) & $27.2(18.7)$ & $44.3(28.9)$ & $48.9(37.7)$ & $<0.001$ \\
\hline \multicolumn{2}{|l|}{ Pack-years smoked during life, n (\%) } & & & $<0.001$ \\
\hline$<20$ & $16(37.2)$ & $49(18.4)$ & $5(14.7)$ & \\
\hline $20-30$ & $15(34.9)$ & $42(15.8)$ & $6(17.7)$ & \\
\hline$>30$ & $12(27.9)$ & $175(65.8)$ & $23(67.6)$ & \\
\hline \multicolumn{2}{|l|}{ Biomass exposure, complete years, n (\%) } & & & 0.501 \\
\hline$\geq 10$ & $16(37.2)$ & $113(41.2)$ & $11(31.4)$ & \\
\hline \multicolumn{2}{|l|}{ Smoking status, n (\%) } & & & 0.728 \\
\hline Never & $2(4.7)$ & $4(1.5)$ & $1(2.9)$ & \\
\hline Former & $23(53.5)$ & $158(58.3)$ & $20(57.1)$ & \\
\hline Current & $18(41.9)$ & $109(40.2)$ & $14(40.0)$ & \\
\hline \multicolumn{5}{|l|}{ Respiratory symptoms present, $\mathrm{n}(\%)$} \\
\hline Cough & $15(34.9)$ & $115(42.0)$ & $10(57.1)$ & $<0.001$ \\
\hline Phlegm & $21(48.8)$ & $116(42.3)$ & $23(65.7)$ & $<0.001$ \\
\hline Wheezing & $43(100.0)$ & $39(14.2)$ & $35(100.0)$ & $<0.001$ \\
\hline Dyspnoea & $17(46.0)$ & $156(61.7)$ & $26(78.8)$ & $<0.001$ \\
\hline mMRC scale, mean (SD) & $0.9(1.2)$ & $1.4(1.3)$ & $1.7(1.3)$ & 0.035 \\
\hline Prior spirometry, n (\%) & $9(20.9)$ & $98(35.8)$ & $16(45.7)$ & $<0.001$ \\
\hline Self-reported diagnosis: COPD, n (\%) & $1(2.3)$ & $63(23.0)$ & $8(22.9)$ & $<0.001$ \\
\hline Self-reported diagnosis: Asthma, n (\%) & $10(23.3)$ & $66(24.1)$ & $16(45.7)$ & $<0.001$ \\
\hline Comorbidity score, mean (SD) & $1.1(1.1)$ & $1.2(1.0)$ & $0.9(0.8)$ & 0.538 \\
\hline \multicolumn{2}{|l|}{ Comorbidity score, n (\%) } & & & 0.067 \\
\hline None & $12(27.9)$ & $61(22.6)$ & $13(37.1)$ & \\
\hline 1 & $22(51.2)$ & $113(41.9)$ & $11(31.4)$ & \\
\hline 2 & $5(11.6)$ & $70(25.9)$ & $11(31.4)$ & \\
\hline $3+$ & $4(9.3)$ & $26(9.6)$ & - & \\
\hline Any exacerbation within the past year, $\mathrm{n}(\%)$ (Yes) & $7(16.3)$ & $25(9.1)$ & $8(22.9)$ & $<0.001$ \\
\hline Number of exacerbations, past year, mean (SD) & $0.4(1.0)$ & $0.2(0.8)$ & $0.4(1.0)$ & 0.002 \\
\hline Hospitalisation due to exacerbation, past year, n (\%) & $1(2.3)$ & $8(2.9)$ & $3(8.6)$ & $<0.001$ \\
\hline
\end{tabular}


Table 1 Characteristics of subjects with COPD (post-bronchodilator FEV $1 / F V C<0.70$ ), asthma (wheezing + reversibility) and ACOS (post-bronchodilator $\mathrm{FEV}_{1} / \mathrm{FVC}<0.70$ plus wheezing + reversibility) (Continued)

\begin{tabular}{|c|c|c|c|c|}
\hline GOLD 2007 stage, n (\%) & & & & $<0.001$ \\
\hline No & $43(100.0)$ & - & - & \\
\hline 1 & - & $50(18.3)$ & $3(8.6)$ & \\
\hline 2 & - & $148(54.0)$ & $21(60.0)$ & \\
\hline 3 & - & $56(20.4)$ & $8(22.9)$ & \\
\hline 4 & - & $20(7.3)$ & $3(8.6)$ & \\
\hline GOLD 2013 stage, n (\%) & & & & $<0.001$ \\
\hline No & $43(100.0)$ & - & - & \\
\hline A & - & $120(43.8)$ & $13(37.1)$ & \\
\hline B & - & $71(25.9)$ & $8(22.9)$ & \\
\hline C & - & $24(8.8)$ & $4(11.4)$ & \\
\hline D & - & $59(21.5)$ & $10(28.6)$ & \\
\hline
\end{tabular}

Abbreviations: BMI Body mass index

Maximum number of missing for each category of ACOS is for dyspnoea (asthma $n=6, \operatorname{COPD} n=21$ and $\operatorname{ACOS} n=2$ )

younger, predominantly female, smoked less and had the highest body mass index. Those in the ACOS group, compared with individuals in the COPD group, were of similar in age, gender (predominantly male), body mass index and pack-years of smoking. The ACOS group had the highest percentage of symptoms (cough, phlegm and dyspnoea), self-reported diagnosis of asthma, exacerbations and hospitalisation due to exacerbation within the past year. A similar distribution of subjects according to GOLD spirometry stage was observed for the COPD and ACOS groups. However, using the new GOLD 2013 staging system (A-D), the ACOS group had a greater proportion of patient categorised as $C$ and D (40\%) compared with the COPD group (30\%) (Table 1). Similar findings to those reported above were observed when the asthma medical diagnosis and $\mathrm{FEV}_{1} / \mathrm{FVC}<0.70$ definition for $\mathrm{ACOS}$ was used (Table 2).

When comparing the three groups, the ACOS patients (defined by wheezing plus reversibility and $\mathrm{FEV}_{1} / \mathrm{FVC}$ $<0.70$ ) had the lowest lung function measurements for pre- and post-bronchodilator $\mathrm{FEV}_{1}$ and FVC (Table 3). The ACOS patients had a higher reversibility (\% change) for $\mathrm{FEV}_{1}$ and $\mathrm{FVC}$ compared with the other two groups (Table 3). Again, similar findings were also found when the other ACOS definition was used (medical diagnosis of asthma and $\mathrm{FEV}_{1} / \mathrm{FVC}<0.70$ ) (Table 4).

Table 5 shows the prevalence ratio and relative risk (crude results and adjusted analysis) for the different phenotypes according to the presence of exacerbations, number of exacerbations, hospitalisations due to exacerbation in the past year and mMRC scale. In the ACOS group defined as wheezing plus reversibility and $\mathrm{FEV}_{1} / \mathrm{FVC}<0.70$ the presence of exacerbations showed crude and adjusted prevalence ratios of 2.68 and 2.20 (COPD as reference group), respectively. The number of exacerbations was not statistically significant for ACOS group (COPD as reference group). The prevalence ratio for hospitalisations and mMRC scale among phenotypes by this definition or when using the asthma medical diagnosis and $\mathrm{FEV}_{1} / \mathrm{FVC}$ $<0.70$ definition were not statistically significant (COPD as reference group). The regression coefficient crude and adjusted analysis for all variables in model * $+\mathrm{FEV}_{1}$ (absolute values, $\mathrm{ml}$ ), for all variables in model $*+\mathrm{FEV}_{1}$ (absolute values, $\mathrm{ml}$ ) + height, for all variables in model * $\mathrm{FEV}_{1}$ (\% predicted according to PLATINO equation) and for all variables in model * + GOLD stages in the different phenotypes is shown in Additional file 1: Table S1.

\section{Discussion}

The principal findings of this study are: first, ACOS prevalence depends on the asthma component definition and the population it is being evaluated in (e.g. general population, obstructive population or COPD population). The lowest prevalence was $2.3 \%$ when ACOS was defined as wheezing plus reversibility and $\mathrm{FEV}_{1} / \mathrm{FVC}<0.70$ in the total population, whereas the highest was $26.5 \%$ when ACOS was defined as previous medical diagnosis of asthma and $\mathrm{FEV}_{1} / \mathrm{FVC}<0.70$ in the COPD population. Second, after adjusting for confounding factors, ACOS defined as $\mathrm{FEV}_{1} / \mathrm{FVC}<0.7$ and wheezing plus reversibility was associated with a higher risk for exacerbations compared with those subjects with COPD.

Proposed definitions for ACOS vary widely and include: a) patients with COPD who have a previous diagnosis of asthma; b) patients with a spirometric COPD definition who have significant reversibility $\left(\mathrm{FEV}_{1} / \mathrm{FVC}<0.70\right.$ and post-bronchodilator increase in $\mathrm{FEV}_{1}$ or $\mathrm{FVC}$ of $200 \mathrm{~mL}$ 
Table 2 Characteristics of subjects with COPD (post-bronchodilator FEV $1 / F V C<0.70$ ), asthma (prior medical diagnosis of asthma) and ACOS (post-bronchodilator FEV 1 /FVC $<0.70$ and prior medical diagnosis of asthma)

\begin{tabular}{|c|c|c|c|c|}
\hline Variables & $\begin{array}{l}\text { Asthma } \\
(N=149)\end{array}$ & $\begin{array}{l}\text { COPD } \\
(N=227)\end{array}$ & $\begin{array}{l}\text { ACOS } \\
(N=82)\end{array}$ & $p$-value \\
\hline Age, years, mean (SD) & $56.3(9.7)$ & $67.8(9.0)$ & $65.0(9.8)$ & $<0.001$ \\
\hline Age, complete years, n (\%) & & & & $<0.001$ \\
\hline $40-49$ & $42(28.2)$ & $4(1.8)$ & $3(3.7)$ & \\
\hline $50-59$ & $60(40.3)$ & $44(19.4)$ & $27(32.9)$ & \\
\hline$\geq 60$ & $47(31.5)$ & $179(78.8)$ & $52(63.4)$ & \\
\hline Gender, male, n (\%) & $43(28.9)$ & $134(59.0)$ & 39 (47.6) & $<0.001$ \\
\hline $\mathrm{BMl}, \mathrm{kg} / \mathrm{m}^{2}$, mean (SD) & $30.0(5.5)$ & $26.3(5.8)$ & $26.4(6.1)$ & $<0.001$ \\
\hline $\mathrm{BMl}, \mathrm{kg} / \mathrm{m}^{2}, \mathrm{n}(\%)$ & & & & $<0.001$ \\
\hline$<25$ & $25(16.8)$ & $104(45.8)$ & $34(41.5)$ & \\
\hline $25-29.9$ & $55(36.9)$ & $75(33.0)$ & $32(39.0)$ & \\
\hline$\geq 30$ & $69(46.3)$ & $48(21.2)$ & $16(19.5)$ & \\
\hline Smoking, pack-years, mean (SD) & $26.8(21.6)$ & $48.3(30.2)$ & $35.0(27.4)$ & $<0.001$ \\
\hline Pack-years smoked during life, n (\%) & & & & $<0.001$ \\
\hline$<20$ & $70(49.7)$ & $27(12.2)$ & $27(34.6)$ & \\
\hline $20-30$ & $23(16.3)$ & $36(16.2)$ & $12(15.4)$ & \\
\hline$>30$ & $48(34.0)$ & $159(71.6)$ & $39(50.0)$ & \\
\hline Biomass exposure, complete years, n (\%) & & & & 0.004 \\
\hline$\geq 10$ & $38(25.5)$ & $96(42.3)$ & $28(34.1)$ & \\
\hline Smoking status, n (\%) & & & & 0.001 \\
\hline Never & $11(7.4)$ & $2(0.9)$ & $3(3.8)$ & \\
\hline Former & $93(62.8)$ & $134(59.3)$ & $44(55.0)$ & \\
\hline Current & $44(29.7)$ & $90(39.8)$ & $33(41.3)$ & \\
\hline \multicolumn{5}{|l|}{ Respiratory symptoms present, n (\%) } \\
\hline Cough & $56(37.6)$ & $95(41.9)$ & $40(48.8)$ & $<0.001$ \\
\hline Phlegm & $40(26.9)$ & $100(44.1)$ & 39 (47.6) & $<0.001$ \\
\hline Wheezing & $40(26.9)$ & $48(21.2)$ & $26(31.7)$ & $<0.001$ \\
\hline Dyspnoea & $83(61.0)$ & $126(59.4)$ & $56(75.7)$ & $<0.001$ \\
\hline mMRC scale, mean (SD) & $1.1(1.3)$ & $1.3(1.3)$ & $1.7(1.3)$ & 0.166 \\
\hline Prior spirometry, n (\%) & $48(32.2)$ & $66(29.1)$ & $48(58.5)$ & $<0.001$ \\
\hline Self-reported diagnosis: COPD, n (\%) & $5(3.4)$ & $46(20.3)$ & $25(30.5)$ & $<0.001$ \\
\hline Self-reported diagnosis: Asthma, n (\%) & $149(100.0)$ & $0(0.0)$ & $82(100.0)$ & $<0.001$ \\
\hline Comorbidity score, mean (SD) & $1.2(1.0)$ & $1.2(0.9)$ & $1.1(1.0)$ & 0.013 \\
\hline Comorbidity score, n (\%) & & & & 0.742 \\
\hline None & $39(26.2)$ & $50(22.3)$ & $24(29.6)$ & \\
\hline 1 & $57(38.3)$ & $92(41.1)$ & $32(39.5)$ & \\
\hline 2 & $36(24.2)$ & $63(28.1)$ & $18(22.2)$ & \\
\hline $3+$ & $17(11.4)$ & $19(8.5)$ & $7(8.6)$ & \\
\hline Any exacerbation within the past year, n (\%) (Yes) & $23(15.4)$ & $19(8.4)$ & $14(17.1)$ & $<0.001$ \\
\hline Number of exacerbations, past year, mean (SD) & $0.4(1.0)$ & $0.2(0.7)$ & $0.4(0.9)$ & $<0.001$ \\
\hline Hospitalisation due to exacerbation, past year, n (\%) & $3(2.0)$ & $8(3.5)$ & $3(3.7)$ & 0.006 \\
\hline GOLD 2007 stage, n (\%) & & & & $<0.001$ \\
\hline
\end{tabular}


Table 2 Characteristics of subjects with COPD (post-bronchodilator FEV $1 / F V C<0.70$ ), asthma (prior medical diagnosis of asthma) and ACOS (post-bronchodilator FEV 1 FVC $<0.70$ and prior medical diagnosis of asthma) (Continued)

\begin{tabular}{|c|c|c|c|c|}
\hline No & 149 (100.0) & - & - & \\
\hline । & - & $43(18.9)$ & $10(12.2)$ & \\
\hline$\|$ & - & $124(54.6)$ & $45(54.9)$ & \\
\hline III & - & $44(19.4)$ & $20(24.4)$ & \\
\hline IV & - & $16(7.1)$ & $7(8.5)$ & \\
\hline GOLD 2013 stage, n (\%) & & & & $<0.001$ \\
\hline No & $149(100.0)$ & - & - & \\
\hline A & - & $104(45.8$ & $29(35.4)$ & \\
\hline B & - & $57(25.1)$ & $22(26.8)$ & \\
\hline$C$ & - & $18(7.9)$ & $10(12.2)$ & \\
\hline$D$ & - & $48(21.2)$ & $21(25.6)$ & \\
\hline
\end{tabular}

Abbreviations: BMI Body mass index

Maximum number of missing for each category of ACOS is for dyspnoea (asthma $n=13, \operatorname{COPD} n=15$ and ACOS $n=8$ )

and $12 \%)$; c) patients with asthma who have persistent airflow obstruction. It is important to recognise whether a patient has ACOS as it may influence the clinical course, long-term outcome, and response to therapy. Other documents such as the Global Initiative for Asthma (GINA)Global Initiative for Chronic Obstructive Lung Disease (GOLD) consensus and the Spanish guideline for COPD have also proposed their own definitions $[35,36]$, however they have not been fully validated in large cohorts.

Using a definition similar to the present study, some authors have assessed ACOS prevalence in the general population. Marsh et al. found a prevalence of ACOS of $11 \%$ in the total population studied and $55 \%$ in the COPD population [18]. However, this study was conducted only in volunteers and had a small sample size.
Using the population-based Spanish EPI-SCAN study data, Miravitlles et al. reported a prevalence of ACOS in the general population of $1.7 \%$, and of $17.4 \%$ in the COPD patients using the previous asthma diagnosis definition [19].

The PLATINO study reports a prevalence based on previous asthma diagnosis and $\mathrm{FEV}_{1} / \mathrm{FVC}<0.70$ criteria in the total population of $2.9 \%$, and a prevalence of $1.8 \%$ using criteria of wheezing plus reversibility and $\mathrm{FEV}_{1} / \mathrm{FVC}$ $<0.70$ [3]. In the same study, in the obstructive population, the prevalence was $13 \%$ by previous asthma diagnosis and $\mathrm{FEV}_{1} / \mathrm{FVC}<0.70$ criteria, and $11.6 \%$ by wheezing plus reversibility and $\mathrm{FEV}_{1} / \mathrm{FVC}<0.70$ [3]. Other authors have assessed the prevalence of ACOS in selected COPD populations $[6,7,22,37]$. The prevalence of ACOS in the

Table 3 Lung function parameters of subjects with COPD (post-bronchodilator FEV $1 / F V C<0.70$ ), asthma (wheezing + reversibility) and ACOS (post-bronchodilator FEV $1 / F V C<0.70$ plus wheezing + reversibility)

\begin{tabular}{|c|c|c|c|c|}
\hline \multirow[t]{2}{*}{ Variables } & \multirow{2}{*}{$\begin{array}{l}\text { Asthma } \\
(N=43)\end{array}$} & \multirow{2}{*}{$\begin{array}{l}\text { COPD } \\
(N=274)\end{array}$} & \multirow{2}{*}{$\begin{array}{l}\text { ACOS } \\
(N=35)\end{array}$} & \multirow[t]{2}{*}{$P$-value } \\
\hline & & & & \\
\hline Pre-bronchodilator $\mathrm{FEV}_{1}, \mathrm{~L}$ & $2.3(0.7)$ & $1.6(0.7)$ & $1.4(0.6)$ & $<0.001$ \\
\hline Pre-bronchodilator $\mathrm{FEV}_{1}, \%$ pred. & $84.3(17.2)$ & $61.8(22.6)$ & $50.7(17.3)$ & $<0.001$ \\
\hline Post-bronchodilator $\mathrm{FEV}_{1}, \mathrm{~L}$ & $2.6(0.7)$ & $1.7(0.7)$ & $1.6(0.6)$ & $<0.001$ \\
\hline Post-bronchodilator $\mathrm{FEV}_{1}, \%$ pred. & $93.1(15.8)$ & $64.7(21.1)$ & $58.8(18.6)$ & $<0.001$ \\
\hline $\mathrm{FEV}_{1}$ change, $\mathrm{mL}$ (absolute) & $237.7(131.7)$ & $73.7(176.7)$ & $215.4(133.7)$ & $<0.001$ \\
\hline $\mathrm{FEV}_{1}$ change, \% (relative) & $11.7(10.1)$ & $8.1(28.9)$ & $17.5(13.3)$ & $<0.001$ \\
\hline Pre-bronchodilator FVC, L & $3.0(0.9)$ & $2.6(0.9)$ & $2.5(0.8)$ & $<0.001$ \\
\hline Pre-bronchodilator FVC, \% pred. & $84.0(17.0)$ & $75.2(19.3)$ & $66.7(17.7)$ & $<0.001$ \\
\hline Post-bronchodilator FVC, L & $3.3(0.9)$ & $2.7(0.9)$ & $2.9(0.8)$ & $<0.001$ \\
\hline Post-bronchodilator FVC, \% pred. & $91.2(15.4)$ & $79.0(18.8)$ & $76.3(17.7)$ & $<0.001$ \\
\hline FVC change, mL (absolute) & $244.9(151.6)$ & $135.0(238.0)$ & $346.6(173.4)$ & $<0.001$ \\
\hline FVC change, \% (relative) & $9.8(9.5)$ & $6.2(11.4)$ & $15.6(9.3)$ & $<0.001$ \\
\hline
\end{tabular}

Values are presented as mean (standard deviation)

Abbreviations: $F E V_{1}$ forced expiratory volume in $1 \mathrm{~s}, F V C$ forced vital capacity 
Table 4 Lung function parameters of subjects with COPD (post-bronchodilator FEV $1 / F V C<0.70$ ), asthma (prior medical diagnosis of asthma) and ACOS (post-bronchodilator $\mathrm{FEV}_{1} / \mathrm{FVC}<0.70$ plus prior medical diagnosis of asthma)

\begin{tabular}{|c|c|c|c|c|}
\hline Variables & $\begin{array}{l}\text { Asthma } \\
(N=149)\end{array}$ & $\begin{array}{l}\text { COPD } \\
(N=227)\end{array}$ & $\begin{array}{l}\text { ACOS } \\
(N=82)\end{array}$ & $p$-value \\
\hline Pre-bronchodilator $\mathrm{FEV}_{1}, \mathrm{~L}$ & $2.4(0.6)$ & $1.6(0.7)$ & $1.4(0.6)$ & $<0.001$ \\
\hline Pre-bronchodilator $\mathrm{FEV}_{1}, \%$ pred. & $90.0(16.3)$ & $62.7(22.1)$ & $54.6(21.9)$ & $<0.001$ \\
\hline Post-bronchodilator $\mathrm{FEV}_{1}, \mathrm{~L}$ & $2.4(0.6)$ & $1.7(0.7)$ & $1.5(0.6)$ & $<0.001$ \\
\hline Post-bronchodilator $\mathrm{FEV}_{1}, \%$ pre. & $92.3(14.2)$ & $65.2(20.9)$ & $60.7(20.7)$ & $<0.001$ \\
\hline $\mathrm{FEV}_{1}$ change, mL (absolute) & $56.7(173.8)$ & $68.1(169.6)$ & $149.6(187.8)$ & $<0.001$ \\
\hline $\mathrm{FEV}_{1}$ change, \% (relative) & $3.5(10.5)$ & $6.0(13.4)$ & $17.9(48.2)$ & $<0.001$ \\
\hline Pre-bronchodilator FVC, L & $3.0(0.7)$ & $2.7(0.9)$ & $2.4(0.8)$ & $<0.001$ \\
\hline Pre-bronchodilator FVC, \% pred. & $88.4(15.6)$ & $75.7(19.2)$ & $70.1(19.1)$ & $<0.001$ \\
\hline Post-bronchodilator FVC, L & $3.0(0.7)$ & $2.8(0.9)$ & $2.6(0.8)$ & $<0.001$ \\
\hline Post-bronchodilator FVC, \% pred. & $89.1(13.9)$ & $79.4(18.6)$ & $76.6(18.8)$ & $<0.001$ \\
\hline FVC change, mL (absolute) & $21.8(200.5)$ & $139.1(249.3)$ & $214.0(207.6)$ & $<0.001$ \\
\hline FVC change, \% (relative) & $1.6(9.6)$ & $6.2(11.8)$ & $10.3(10.3)$ & $<0.001$ \\
\hline
\end{tabular}

Values are presented as mean (standard deviation)

Abbreviations: $F E V_{1}$ forced expiratory volume in $1 \mathrm{~s}, F V C$ forced vital capacity

COPDGene study was $12.6 \%$ using self-reported asthma criteria [7], and similar results have been reported elsewhere [6]. Recently, Cosio et al. reported an ACOS prevalence of $15 \%$ in a COPD Spanish cohort of over 800 patients using one major criterion for asthma definition (reversibility $>400 \mathrm{~mL}$ and $15 \%$ plus medical history of asthma) or two minor criteria (blood eosinophils $>5 \%$, IgE $>100 \mathrm{IU} / \mathrm{mL}$, or two separate bronchodilator tests $>200 \mathrm{~mL}$ and 12\%) [22]. A higher prevalence (25\%) was reported in the ECLIPSE cohort when using their primary study definition of COPD patients answering "yes" to the question "Have you ever had asthma?" [37].

Little information exists regards the prevalence of ACOS in the primary care setting. As expected, the prevalence varied depending on the method by which ACOS was defined. Barrechenguren et al. reported a prevalence of $5.4 \%$ using the previous diagnosis of asthma in newly diagnosed patients with COPD [38]. In a separate study, the same authors found a higher ACOS prevalence in COPD patients with a history of asthma (10.8\%) [39]. Others have reported a prevalence of $5.5 \%$ using a history of asthma in the total study population, and $19.1 \%$ using a restrictive analysis (asthma defined by reversibility criteria) in the COPD population [40].

The findings of the present study are consistent with those reported in some general and selected COPD populations that have used the previous diagnosis of asthma plus spirometric COPD to define ACOS $[3,5,7,30]$. The comparison with the PLATINO study deserves special consideration as this is another study from Latin America that use the same two ACOS definitions in the same population [3]. The most important difference between the two studies that needs to be highlighted is that the PLATINO study was a larger population-based (general population) study, whereas PUMA is a study in a primary care population at risk for COPD; as a result of these being two different populations, differences in the results are to be expected. The prevalence of ACOS by both definitions reported here in the PUMA study (population at risk for COPD) were slightly higher than those reported in the PLATINO study.

The above-mentioned findings support the concept that the criteria used to define ACOS, as well as the population used to calculate the prevalence, have a significant influence on prevalence; it is thus essential to know this information when interpreting the results of other studies. The discrepancies observed with the findings of primary care studies could be partially explained by the selection of participating patients (only newly diagnosed COPD patients and/or a younger population), and the ACOS definition used [38-40]. However, when spirometric COPD diagnosis and asthma defined by reversibility was used to define ACOS elsewhere [40], the prevalence was similar to our results in the COPD population. Another important aspect to highlight is that the Latin American population has a very distinct characteristic of being exposed to biomass fuel. There is no literature on biomass exposure and ACOS. In the present study, more than a third of the patients in each group had biomass exposure and irrespective of the definition used, approximately $3 \%$ of patients with ACOS had no smoking history. The size of the PUMA sample does not allow us to analyse the characteristics of ACOS patients due to biomass exposure; therefore, futures studies in regions with high biomass exposure, such as 
Table 5 Prevalence ratio and relative risk (crude and adjusted analysis) for exacerbations, hospitalisations due to exacerbation in the past year and $\mathrm{mMRC}$ scale in the different phenotypes

\begin{tabular}{|c|c|c|c|c|c|}
\hline & Asthma & $p$-value & COPD & ACOS & $p$-value \\
\hline \multicolumn{6}{|c|}{ Asthma defined by wheezing + reversibility } \\
\hline \multicolumn{6}{|c|}{ Exacerbations in the past year (yes/no) } \\
\hline Unadjusted - PR (95\% Cl) & $1.85(0.85 ; 4.06)$ & 0.122 & 1.00 & $2.68(1.30 ; 5.52)$ & 0.007 \\
\hline Adjusted $^{\mathrm{a}}-\mathrm{PR}(95 \% \mathrm{Cl})$ & $2.24(0.92 ; 5.45)$ & 0.075 & 1.00 & $2.20(1.10 ; 4.39)$ & 0.026 \\
\hline \multicolumn{6}{|c|}{ Number of exacerbations in the past year } \\
\hline Unadjusted - RR (95\% Cl) & $1.77(0.72 ; 4.34)$ & 0.210 & 1.00 & $2.10(0.90 ; 4.90)$ & 0.086 \\
\hline Adjusted $^{\mathrm{a}}-\mathrm{RR}(95 \% \mathrm{Cl})$ & $2.84(0.94 ; 8.61)$ & 0.065 & 1.00 & $1.64(0.78 ; 3.44)$ & 0.191 \\
\hline \multicolumn{6}{|l|}{ Hospitalisations in the past year } \\
\hline Unadjusted - PR (95\% Cl) & $0.76(0.10 ; 5.96)$ & 0.795 & 1.00 & $2.89(0.80 ; 10.39)$ & 0.104 \\
\hline Adjusted $^{\mathrm{a}}-\mathrm{PR}(95 \% \mathrm{Cl})$ & $3.57(0.48 ; 26.59)$ & 0.214 & 1.00 & $1.65(0.53 ; 5.06)$ & 0.385 \\
\hline \multicolumn{6}{|l|}{ mMRC scale } \\
\hline Unadjusted - RR (95\% Cl) & $0.64(0.41 ; 0.99)$ & 0.289 & 1.00 & $1.17(0.88 ; 1.56)$ & 0.046 \\
\hline Adjusted $^{\mathrm{a}}-\mathrm{RR}(95 \% \mathrm{Cl})$ & $0.73(0.48 ; 1.12)$ & 0.149 & 1.00 & $1.22(0.92 ; 1.12)$ & 0.176 \\
\hline \multicolumn{6}{|c|}{ Asthma defined as medical diagnosis } \\
\hline \multicolumn{6}{|c|}{ Exacerbations in the past year (yes/no) } \\
\hline Unadjusted - PR (95\% Cl) & $1.80(1.01 ; 3.20)$ & 0.046 & 1.00 & $1.80(0.91 ; 3.53)$ & 0.089 \\
\hline Adjusted $^{\mathrm{a}}-\mathrm{PR}(95 \% \mathrm{Cl})$ & $1.57(0.75 ; 3.27)$ & 0.231 & 1.00 & $1.29(0.64 ; 2.60)$ & 0.480 \\
\hline \multicolumn{6}{|c|}{ Number of exacerbations in the past year } \\
\hline Unadjusted - RR (95\% Cl) & $1.92(0.99 ; 3.68)$ & 0.054 & 1.00 & $1.68(0.77 ; 3.66)$ & 0.191 \\
\hline Adjusted $^{\mathrm{a}}-\mathrm{RR}(95 \% \mathrm{Cl})$ & $2.01(0.94 ; 4.30)$ & 0.072 & 1.00 & $1.32(0.60 ; 2.88)$ & 0.490 \\
\hline \multicolumn{6}{|l|}{ Hospitalisations in the past year } \\
\hline Unadjusted - PR (95\% Cl) & $0.58(0.16 ; 2.16)$ & 0.419 & 1.00 & $1.07(0.29 ; 3.92)$ & 0.923 \\
\hline Adjusted $^{\mathrm{a}}-\mathrm{PR}(95 \% \mathrm{Cl})$ & $0.68(0.17 ; 2.69)$ & 0.581 & 1.00 & $0.72(0.21 ; 2.44)$ & 0.596 \\
\hline \multicolumn{6}{|l|}{ mMRC scale } \\
\hline Unadjusted - RR (95\% Cl) & $0.90(0.72 ; 1.14)$ & 0.311 & 1.00 & $1.24(0.98 ; 1.56)$ & 0.052 \\
\hline Adjusted $^{\mathrm{a}}-\mathrm{RR}(95 \% \mathrm{Cl})$ & $0.97(0.75 ; 1.25)$ & 0.799 & 1.00 & $1.20(0.96 ; 1.21)$ & 0.108 \\
\hline
\end{tabular}

${ }^{a}$ Adjusted for age, sex, skin colour, body mass index, schooling, comorbidity score, pack-years and any treatment (bronchodilator or corticosteroid)

Abbreviations: $P R$ prevalence ratio, $R R$ relative risk

Latin America, aimed at characterizing this group of patients are warranted.

Two recent systematic reviews and meta-analyses indicate that ACOS patients may have more symptoms, more frequent exacerbations and hospitalisations, worse HRQOL and higher healthcare costs than patients with only asthma or COPD [20, 21]. Similar to patients with COPD, ACOS patients appear to have a high occurrence of comorbidities, including diabetes. In agreement with the results of these systematic reviews, we found the spirometry plus symptom-based (wheezing plus reversibility and $\left.\mathrm{FEV}_{1} / \mathrm{FVC}<0.70\right)$ definition identify a clinical phenotype with more frequent exacerbations. Also, in agreement with other results, we did not find any difference in the number of comorbidities between the groups [39]. In the present study, the ACOS patients (defined by wheezing plus reversibility and $\mathrm{FEV}_{1} / \mathrm{FVC}$ $<0.70)$ had the lowest lung function measurements. These findings are consistent with other studies in populationbased sample that reported lower level of lung function in the ACOS subjects compared with asthma and COPD groups $[3,41]$. As has been mentioned previously, there is no universal definition for ACOS. However, this is a phenotype recognised as a different COPD subpopulation with important therapeutic implications. The GINAGOLD consensus recommends the use of inhaled corticosteroids (ICS) in patients with suspected ACOS [34]. However, ICS therapy has been linked with increased risk of pneumonia in COPD patients [42, 43], so it is crucial to be as accurate as possible with the prevalence of ACOS as well as determining the most appropriate definition to avoid over-diagnosis and subsequent overuse of ICS in patients with COPD.

Finally, when considering and interpreting the current findings, it is important to be aware of the following study limitations: these results are not generalizable to all Latin 
American countries as the study was only performed in four countries; it is possible that some results did not reach statistical significance as a result of sample size and lack of power, despite the efforts made to ensure a representative sample. Nevertheless, the procedure used was the most reasonable in view of the operational possibilities in each country; this was a transversal study and so was only designed to evaluate the characteristics of the patients and not the follow-up; we did not assess any pathophysiological link among ACOS, COPD and asthma, or a pathway that could explain the characteristics of the ACOS patients. It is important to note that the PUMA centres were not randomised, so sites selection did not follow a representative sampling of national primary care practice. In addition, other limitations to consider are that the diagnosis of asthma was, in part, based on patient recall and this may influence the true "incidence" of ACOS, and "wheezing" was obtained from questionnaires and was not directly observed by a physician. Finally, it is important to highlight that although wheezing is a hallmark of asthma, it often occurs in COPD, especially during exacerbations. Hence, if a patient has wheezing there is a possibility that this symptom originated from a COPD exacerbation; therefore, is not entirely surprising that patients with "ACOS" had higher incidence of exacerbations. Another limitation is the lack of a variable that could indicate severity. We performed a sensitivity analysis including $\mathrm{FEV}_{1}$ in the model as a proxy of severity, but the statistical model became unstable with variance inflation factors higher than 10 . It should be highlighted that the direction of the association did not change adding $\mathrm{FEV}_{1}$. Therefore, we opted to maintain the model with the best quality criteria for the adjustment and did not include $\mathrm{FEV}_{1}$ as a possible proxy for severity of COPD in the model.

\section{Conclusions}

This large report of ACOS in Latin America indicates that the variability in the ACOS prevalence is clearly linked with the definitions used for asthma and COPD, and the population being studied. The spirometry plus symptombased (wheezing plus reversibility and $\mathrm{FEV}_{1} / \mathrm{FVC}<0.70$ ) definition identifies a clinical phenotype with more frequent exacerbations, which is probably associated with a different management and treatment approach. Further evidence, including prospective longitudinal studies focusing in the validation of the diagnostic criteria with more standardised outcome measures, is clearly needed to clarify the burden of this disease.

\section{Additional file}

Additional file 1: Table S1. Prevalence ratio and relative risk (crude and adjusted analyses for all variables in the model $+\mathrm{FEV}^{1}$ ) for exacerbations, hospitalisations due to exacerbation in the past year and mMRC scale in the different phenotypes. The regression coefficient crude and adjusted analyses for all variables in model ${ }^{*}+\mathrm{FEV}_{1}$ (absolute values, $\left.\mathrm{ml}\right)$, for all variables in model * $+\mathrm{FEV}_{1}$ (absolute values, $\mathrm{ml}$ ) + height, for all variables in model * + $\mathrm{FEV}_{1}$ (\% predicted according to PLATINO equation) and for all variables in model * + GOLD stages in the different phenotypes. (DOCX $17 \mathrm{~kb}$ )

\section{Abbreviations}

ACOS: Asthma-COPD overlap syndrome; COPD: Chronic obstructive pulmonary disease; $F_{E V}$ : Forced expiratory volume in $1 \mathrm{~s}$; FVC: Forced vital capacity; GINA: Global initiative for asthma; GOLD: Global initiative for chronic obstructive lung disease; HRQOL: Health-related quality of life; ICS: Inhaled corticosteroid

\section{Acknowledgements}

Editorial support was provided by Dr lan Wright, of Wright Medical Communications Ltd, and funded by AstraZeneca.

\section{Funding}

This observational study was funded by AstraZeneca Latin America. AstraZeneca had no input into the study design, analysis and interpretation of the results.

\section{Availability of data and materials}

The datasets used and/or analysed during the current study available from the corresponding author on reasonable request.

\section{Authors' contributions}

Conceived and designed the experiments: MMO, MVLV, ACH, ES, JCM. Performed the experiments: MMO, ACH, MVLV, ES. Analysed the data: MMO, MVLV, MELC. Contributed reagents/materials/analysis tools: MMO, ACH, MVLV, MELC, JCM. Drafted the manuscript: MMO, MVLV, MELC. All authors provided critical revision of the manuscript and read and approved the final version.

\section{Competing interests}

All authors declared that they have no real or perceived competing interests with the exception of JCM who is an employee of AstraZeneca Latin America.

\section{Consent for publication \\ Not applicable.}

\section{Ethics approval and consent to participate}

The ethics committees that approved the protocol were: Comité de Bioética, Iniciativa Y Reflexion Bioethica, Buenos Aires, Argentina; Comité de Ética en Investigación, Fundación Neumológica Colombiana, Bogota, Colombia; Comité Cientifico Acta No. 02-12, Direccion Nacional de Sanidad de Las Fuerzas Armadas, Direccion Tecnica, Montevideo, Uruguay; and Centro Nacional de Bioética, Junta Directiva, Caracas, Venezuela. All participants provided written informed consent.

\section{Publisher's Note}

Springer Nature remains neutral with regard to jurisdictional claims in published maps and institutional affiliations.

\section{Author details}

${ }^{1}$ Servicio de Neumonología, Hospital Universitario de Caracas, Facultad de Medicina, Los Chaguaramos, 1030, Universidad Central de Venezuela, Caracas, Venezuela. ${ }^{2}$ Universidad de la República, Facultad de Medicina, Hospital Maciel, Montevideo, Uruguay. ${ }^{3}$ Fundación Neumológica Colombiana, Bogotá, Colombia. ${ }^{4}$ Hospital de Rehabilitación Respiratoria María Ferrer, Buenos Aires, Argentina. ${ }^{5}$ AstraZeneca Medical Department, Medellín, Colombia.

Received: 24 September 2016 Accepted: 18 April 2017

Published online: 21 April 2017

\section{References}

1. Diaz-Guzman E, Khosravi M, Mannino DM. Asthma, chronic obstructive pulmonary disease, and mortality in the U.S. population. COPD. 2011;8:400-7.

2. Hardin M, Silverman EK, Barr RG, et al. The clinical features of the overlap between COPD and asthma. Respir Res. 2011;12:127. 
3. Menezes AM, MontesdeOca M, Pérez-Padilla R, et al. Increased risk of exacerbation and hospitalization in subjects with an overlap phenotype: COPD-asthma. Chest. 2014;145:297-304.

4. de Marco R, Pesce G, Marcon A, et al. The coexistence of asthma and chronic obstructive pulmonary disease (COPD): prevalence and risk factors in young, middle-aged and elderly people from the general population. PLoS One. 2013;8:e62985.

5. Wurst KE, Kelly-Reif K, Bushnell GA, Pascoe S, Barnes N. Understanding asthmachronic obstructive pulmonary disease overlap syndrome. Respir Med. 2016; 110:1-11.

6. Izquierdo-Alonso JL, Rodriguez-Gonzálezmoro JM, de Lucas-Ramos P, et al. Prevalence and characteristics of three clinical phenotypes of chronic obstructive pulmonary disease (COPD). Respir Med. 2013;107:724-31.

7. Hardin M, Cho M, McDonald ML, et al. The clinical and genetic features of COPD-asthma overlap syndrome. Eur Respir J. 2014:44:341-50.

8. Lamprecht B, McBurnie MA, Vollmer WM, et al. COPD in never smokers: results from the population-based burden of obstructive lung disease study. Chest. 2011;139:752-63.

9. Andersén H, Lampela P, Nevanlinna A, Säynäjäkangas O, Keistinen T. High hospital burden in overlap syndrome of asthma and COPD. Clin Respir J. 2013;7:342-6.

10. Iwamoto $\mathrm{H}, \mathrm{GaO} J$, Koskela J, et al. Differences in plasma and sputum biomarkers between COPD and COPD-asthma overlap. Eur Respir J. 2014:43:421-9.

11. Kitaguchi Y, Komatsu Y, Fujimoto K, Hanaoka M, Kubo K. Sputum eosinophilia can predict responsiveness to inhaled corticosteroid treatment in patients with overlap syndrome of COPD and asthma. Int J Chron Obstruct Pulmon Dis. 2012;7:283-9.

12. Blanchette CM, Broder M, Ory C, Chang E, Akazawa M, Dalal AA. Cost and utilization of COPD and asthma among insured adults in the US. Curr Med Res Opin. 2009;25:1385-92.

13. Wurst KE, Shukla A, Muellerova H, Davis KJ. Respiratory pharmacotherapy use in patients newly diagnosed with chronic obstructive pulmonary disease in a primary care setting in the UK: a retrospective cohort study. COPD. 2014;11:521-30.

14. Pleasants RA, Ohar JA, Croft JB, et al. Chronic obstructive pulmonary disease and asthma-patient characteristics and health impairment. COPD. 2014;11:256-66.

15. Shaya FT, Dongyi D, Akazawa MO, et al. Burden of concomitant asthma and COPD in a Medicaid population. Chest. 2008;134:14-9.

16. Rhee $\mathrm{CK}$, Yoon $\mathrm{HK}$, Yoo KH, et al. Medical utilization and cost in patients with overlap syndrome of chronic obstructive pulmonary disease and asthma. COPD. 2014;11:163-70.

17. Kauppi $\mathrm{P}$, Kupiainen $\mathrm{H}$, Lindqvist $\mathrm{A}$, et al. Overlap syndrome of asthma and COPD predicts low quality of life. J Asthma. 2011;48:279-85.

18. Marsh SE, Travers J, Weatherall M, et al. Proportional classifications of COPD phenotypes. Thorax. 2008;63:761-7.

19. Miravitlles M, Soriano JB, Ancochea J, et al. Characterisation of the overlap COPD-asthma phenotype. Focus on physical activity and health status. Respir Med. 2013;107:1053-60

20. Nielsen M, Barnes CB, Ulrik CS. Clinical characteristics of the asthma-COPD overlap syndrome-a systematic review. Int J Chron Obstruct Pulmon Dis. 2015:10:1443-54.

21. Alshabanat A, Zafari Z, Albanyan O, Dairi M, FitzGerald JM. Asthma and COPD Overlap Syndrome (ACOS): A Systematic Review and Meta Analysis. PLoS One. 2015;10:e0136065.

22. Cosio BG, Soriano JB, López-Campos JL, et al. Defining the Asthma-COPD Overlap Syndrome in a COPD Cohort. Chest. 2016;149:45-52.

23. Kiljander T, Helin T, Venho K, Jaakkola A, Lehtimäki L. Prevalence of asthmaCOPD overlap syndrome among primary care asthmatics with a smoking history: a cross-sectional study. NPJ Prim Care Respir Med. 2015:25:15047.

24. Schiavi E, Stirbulov R, Hernández Vecino R, Mercurio S, Di Boscio V. COPD screening in primary care in four Latin American countries: methodology of the PUMA Study. Arch Bronconeumol. 2014;50:469-74.

25. López Varela MV, Montes de Oca M, Rey A, Casas A, Stirbulov R, Di Boscio V. Opportunistic COPD case-finding in primary care of four Latin America countries. Developing a simple screening tool: The PUMA study. Respirology. 2016;doi:10.1111/resp.12834.

26. Casas A, Montes de Oca M, López Varela MV, Aguirre C, Schiavi E, Jardim JR. COPD underdiagnosis and misdiagnosis in a high-risk primary care population in four Latin American countries. A key to enhance disease diagnosis: The PUMA study. PLoS One. 2016:11:e0152266.
27. Montes de Oca M, Lopez Varela MV, Jardim J, Stirvulov R, Surmont F. Bronchodilator treatment for COPD in primary care of four Latin America countries: The multinational, cross-sectional, non-interventional PUMA study. Pulm Pharmacol Ther. 2016:38:10-6.

28. Rodriguez J, Jiang R, Johnson WC, Mackenzie BA, Smith LJ, Barr RG. The association of pipe and cigar use with cotinine levels, lung function, and airflow obstruction: a cross-sectional study. Ann Intern Med. 2010;152: 201-10.

29. Perez-Padilla R, Regalado J, Vedal S, et al. Exposure to biomass smoke and chronic airway disease in Mexican women. A case-control study. Am J Respir Crit Care Med. 1996:154:701-6.

30. Caballero A, Torres-Duque CA, Jaramillo C, et al. Prevalence of COPD in five Colombian cities situated at low, medium, and high altitude (PREPOCOL study). Chest. 2008;133:343-9.

31. Menezes AM, Perez-Padilla R, Jardim J, et al. Chronic obstructive pulmonary disease in five Latin American cities (the PLATINO study): a prevalence study. Lancet. 2005;366:1875-81.

32. López Varela MV, Montes de Oca M, Halbert R, et al. Comorbidities and health status in individuals with and without COPD in five Latin American cities: the PLATINO study. Arch Bronconeumol. 2013;49:468-74.

33. American Thoracic Society. Lung function testing: selection of reference values and interpretative strategies. Am Rev Respir Dis. 1991;144:1202-28.

34. Vestbo J, Hurd SS, Agustí AG, et al. Global strategy for the diagnosis, management, and prevention of chronic obstructive pulmonary disease: GOLD executive summary. Am J Respir Crit Care Med. 2013; 187:347-65.

35. Reddel HK, Bateman ED, Becker A, et al. A summary of the new GINA strategy: a roadmap to asthma control. Eur Respir J. 2015;46:622-39.

36. Miravitlles M, Soler-Cataluña JJ, Calle M, et al. Spanish guideline for COPD (GesEPOC). Update 2014. Arch Bronconeumol. 2014;50 Suppl 1:1-16.

37. Wurst KE, Rheault TR, Edwards L, Tal-Singer R, Agusti A, Vestbo J. A comparison of COPD patients with and without ACOS in the ECLIPSE study. Eur Respir J. 2016:47:1559-62.

38. Barrecheguren M, Monteagudo M, Ferrer J, et al. Treatment patterns in COPD patients newly diagnosed in primary care. A population-based study. Respir Med. 2016;111:47-53.

39. Barrecheguren $M$, Román-Rodríguez $M$, Miravitlles $M$. Is a previous diagnosis of asthma a reliable criterion for asthma-COPD overlap syndrome in a patient with COPD? Int J Chron Obstruct Pulmon Dis. 2015:10:1745-52.

40. van Boven JF, Román-Rodríguez M, Palmer JF, Toledo-Pons N, Cosío BG, Soriano JB. Comorbidome, Pattern, and Impact of Asthma-COPD Overlap Syndrome in Real Life. Chest. 2016;149:1011-20.

41. Chung JW, Kong KA, Lee JH, Lee SJ, Ryu YJ, Chang JH. Characteristics and self-rated health of overlap syndrome. Int J Chron Obstruct Pulmon Dis. 2014;9:795-804

42. Ernst P, Saad N, Suissa S. Inhaled corticosteroids in COPD: the clinical evidence. Eur Respir J. 2015:45:525-37.

43. Kew KM, Seniukovich A. Inhaled steroids and risk of pneumonia for chronic obstructive pulmonary disease. Cochrane Database Syst Rev. 2014;3:CD010115.

\section{Submit your next manuscript to BioMed Central and we will help you at every step:}

- We accept pre-submission inquiries

- Our selector tool helps you to find the most relevant journal

- We provide round the clock customer support

- Convenient online submission

- Thorough peer review

- Inclusion in PubMed and all major indexing services

- Maximum visibility for your research

Submit your manuscript at www.biomedcentral.com/submit 